This item was submitted to Loughborough's Research Repository by the author.

Items in Figshare are protected by copyright, with all rights reserved, unless otherwise indicated.

\title{
The use of structured relationship modelling techniques as a tool to elicit customizable product features
}

PLEASE CITE THE PUBLISHED VERSION

\section{PUBLISHER}

(C) IMechE / Professional Engineering Publishing

\section{VERSION}

VoR (Version of Record)

\section{LICENCE}

CC BY-NC-ND 4.0

\section{REPOSITORY RECORD}

Barrass, David F., Jonathan R. Roberts, Roy Jones, Richard J.M. Hague, and Phill M. Dickens. 2019. "The Use of Structured Relationship Modelling Techniques as a Tool to Elicit Customizable Product Features". figshare. https://hdl.handle.net/2134/4739. 
This item was submitted to Loughborough's Institutional Repository (https://dspace.lboro.ac.uk/) by the author and is made available under the following Creative Commons Licence conditions.

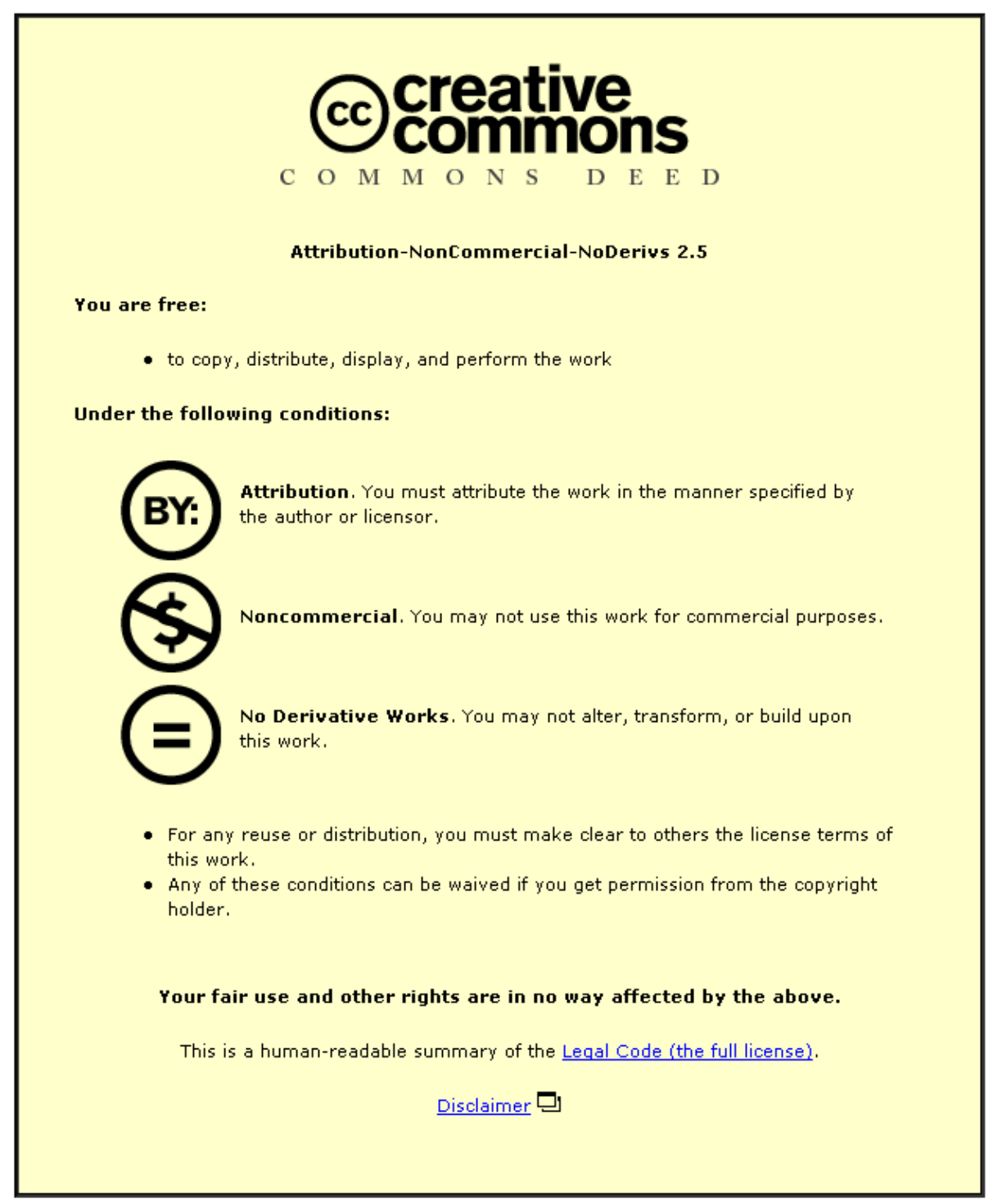

For the full text of this licence, please go to: http://creativecommons.org/licenses/by-nc-nd/2.5/ 


\title{
The use of structured relationship modelling techniques as a tool to elicit customizable product features
}

D F Barrass*, J Roberts, R Jones, R Hague, and P Dickens

Department of Mechanical and Manufacturing Engineering, Loughborough University, Leicestershire, UK

The manuscript was received on 6 June 2007 and was accepted after revision for publication on 5 October 2007.

DOI: 10.1243/09544062JMES761

\begin{abstract}
The current article discusses a procedure for the elicitation of product requirements from a target group of users. The use of the method to help develop products with customizable elements is evaluated as this is one area in which this procedure is considered effective. The technique of forming a structured relationship model uses open-ended questions to elicit subject's sensations when using the product under investigation. Inductive content analysis is then performed on the responses to allow a structured relationship model to be developed.
\end{abstract}

Keywords: design, rapid manufacturing, customization, tennis, perception

\section{INTRODUCTION}

The presence of personally configurable products is becoming increasingly widespread in the consumer product market. The development of new manufacturing processes and the increased use of computeraided design and manufacture are helping to make these developments possible. In the sports equipment market, product personalization or customization has been conducted for many years for elite level athletes. Sports equipment manufacturers are known to produce equipment to the athlete's exact specification or use methodologies to fit their equipment to the athlete's anthropometric measurements. However, some of these equipment customization procedures have begun to emerge with equipment available for the general public. Premium golf clubs are often sold with the possibility of adjustments of the equipment for the customer. Shoes and apparel have become customizable using services such as Nike iD (www.nikeid.com) to alter the appearance and add personal affects to the products. The major reasons for the introduction of customization of consumer products to the public are to increase a product's value, improve customer satisfaction, and increase a company's market differentiation.

\footnotetext{
*Corresponding author: Department of Mechanical and Manufacturing Engineering, Loughborough University, Loughborough, Leicestershire LE11 3TU, UK. email: dfbarrass@gmail.com
}

According to Campbell [1] , different levels of customization are possible, each of which is achieved using different methods. The most intensive of these is the production of a wholly bespoke product: one that has been designed from conception for an individual customer and aims to satisfy the requirements of that customer and no others. This situation occurs rarely, in examples such as uniquely commissioned jewellery. At the other end of the spectrum is the modification of one feature of an otherwise standard product. This can be achieved, for example, by changing the product's colour or size and providing thousands of options to satisfy one person's requirements or a range of options to satisfy a group of customers. Between these two extremes lie the concept of modularization. In this process, a highly customized product can be produced by presenting the customer with several options for a range of features of the product. This generates thousands of potential product configurations to satisfy the customer. This process has been used for many years by the automotive industry to satisfy consumer needs. In this approach, none of the product options are produced for a specific user, but a wide variety of product elements are offered; these can then be combined to provide a single product with multiple options for the consumer. This practice is popular as the various product elements can be produced using mass-manufacturing methods and then combined as required to provide the wealth of choice to the consumer. 
The current article aims to investigate a novel approach to determine the features or characteristics of a product identified as important by the user. This approach should address some of the limitations of other techniques, such as user interviews and focus groups, for gathering user information. For customization of a product to be popular, it must be provided with features that the consumer considers important. Duray [2] recommends that if customers are involved in the early stages of a production cycle, then it is possible for the product to be highly customized. Ulrich and Eppinger [3] state that the first stages of concept development should be the identification of customer needs and the establishment of target specifications. Once the features are identified, they can either be fed directly into a formalized product design specification or refined through further investigation to provide quantitative information for target specifications. The requirements of a product design specification can be quantitative such as product weight or balance point or subjective 'I want this product to feel expensive'. Some of the qualities may be specific to a large group of users 'I want this product to be safe to use' or specific to an individual 'it must fit in my hand'. It is the identification of this information that helps to develop a good product. A product that is easy to change does not consequently offer good customizability. The contribution of the change to customer satisfaction is another important factor. A product where modifying the base design is difficult but that produces a high customer perceived value may lend itself to better customizability than a product that is easy to change but is less appreciated by the customer [4].

For effective customization, the purpose of identifying the important product features is clear. It is important regardless of the customization method used: bespoke or modularized, which the design is focused on those elements of the product which the user perceives as the most important or possesses the most influence on product use. In this study, a method to identify product features is described using a case study of customizing tennis racket handles; this formed part of an extensive investigation into the feasibility of using rapid manufacturing to develop a customizable handle system for sports grips [5]. Rapid manufacturing is a relatively novel approach born out of rapid prototyping. In this process, parts are manufactured, using a variety of techniques, directly from a three-dimensional computer-aided design (CAD) model. This removes the need for tooling and allows simple manipulation of the CAD model to produce product iterations. The flexibility of these technologies was the main factor behind their selection for the manufacture of customized equipment. Sports equipment was chosen as a strong candidate area for customization, because of the nature of these items typically being proprietary for individual athletes who, in many cases, treat the equipment as an extension of their own limbs. Measures that help to improve this link between the athlete and equipment are likely to improve performance and receive acclaim.

\section{IDENTIFYING PRODUCT NEEDS}

It is important that the initial identification of the customer needs and development of the target specifications are approached systematically as this poses lasting implications on the concept selection and development.

Ulrich and Eppinger [3] discuss the requirements of a methodology to comprehensively identify customer needs. The goals of the methodology include the following.

1. Ensure that the product is focused on customer needs.

2. Identify hidden needs as well as explicit needs.

3. Provide a fact base to justify product specifications.

4. Create an archival record of needs activity of the development process.

5. Ensure no critical customer need is missed or forgotten.

6. Develop a common understanding of the customer needs.

The purpose of employing this methodology is to create a quality information channel between the target customers and those that influence the product (designers, engineers, etc.), so that they can interact with customers and understand the product use. Needs are different to product specifications in that they are largely independent of the manufactured product, whereas specifications depend on the product concept selected and what is technically and economically feasible. There are many methods that can be used to generate and gather raw data with regard to customer needs and perceptions of products and equipment. Typically, these data are then used by designers and engineers for product development by integrating them into concept selection matrices or using structured techniques such as quality function deployment (QFD). Conventional methods of data collection include interviews, focus groups, observation of the product in use, data from complaint logs or customer response databases, and other variations of these approaches. The use of surveys to gather initial raw data is not appropriate in this situation, as they do not provide sufficient information and can frequently become based on previous perceived needs and result in latent needs 
being ignored. It is important that the initial gathering of raw data remains receptive to customers' information.

The method selected for this study was the creation of a structured relationship model; this is an alternative technique to the methodologies of focus groups and interviews and has been developed to address some of the shortcomings of these techniques. The model comprises two stages: the collection of the subject data and the formation of the model, which is a means to formally represent the results.

\section{FORMATION OF A STRUCTURED RELATIONSHIP MODEL}

Roberts et al. [6] first developed a formalized approach for eliciting and structuring players' descriptions of sports equipment, using qualitative methods of inquiry, and applied it to golfer's perceptions when using drivers. The structured relationship model provides a diagrammatic representation of product characteristics that influence a user's perception and how these characteristics interact to form the complex network that represents a players overall perception of the product. Typical vocabulary used by the subject group to describe the various sensations or product properties is also documented, which can be used to help increase comprehension in designer-user interactions. The techniques used in Roberts et al. [6] study were in part developed from other sports-based studies, which used qualitative techniques to examine player's thoughts, feelings, and perceptions [7-11]. These studies investigated the mental and emotional aspects of participation in sporting activities. Gould et al. $[\mathbf{7}, \mathbf{8}]$ investigated Olympic wrestlers; their mental preparations strategies, pre-competitive cognition, and their competitive thoughts and affect. Hanton and Jones [9] investigated elite swimmers; the cognitive skills and strategies underlying their interpretations of their pre-race feelings and thoughts. Scanlan et al. $[10,11]$ investigated figure skaters; their sources of enjoyment and stress and the roles that significant people in their lives played in their experiences. Roberts et al. [6] used the techniques and recommendations from these studies to develop a methodology suitable for investigating athletes' thoughts and feelings towards equipment and its role in their performance. The techniques developed by Roberts et al. [6] have been further used to develop structured relationship models for tennis balls [12], hockey pitches [13], and unpublished models for cricket bats, tennis rackets, soccer, and golf balls. The merits of the structured relationship modelling approach are the following.

1. It observes subject using the product.
2. It allows subject to discuss characteristics that they like and dislike.

3. It allows the subject to identify improvements that they would make.

4. The process is flexible and subject led; therefore, subject's responses do not become constrained and latent needs can become expressed.

5. It allows the subject and interviewer the use of visual and tactile stimuli.

6. It provides the interviewer freedom to probe subject responses.

7. Non-verbal information can be reported.

This process offers advantages over the traditional information gathering techniques of interviews and focus groups. The concurrent nature of the technique provides advantages, as the users' responses can be probed while using the product under investigation. The introduction of the product and familiar surroundings to the data collection stage of this technique help to develop a relationship between the investigator and subject, with the process allowing more freedom for users to articulate their responses. The whole structure of the technique has been developed to ensure that participants are not led or pressured into certain responses, which is a common criticism of interview techniques.

\subsection{Methodology}

To apply this technique to investigate tennis racket handles, eight identical premium racket frames with different configuration handles and grips were prepared. Three handle/grip factors were identified as variables and were configured on the test rackets to help stimulate the subject to provide responses about the sensations elicited from the handle during play. The following factors were identified.

1. Grip surface - eight different grip wraps were selected for the testing.

2. Handle size - four different handle sizes were used.

3. Handle shape - four different handle shapes were used.

Identical racket frames and stringing were used to help ensure that subjects only perceived differences in racket handle/grip and therefore would only discuss perceptions elicited by the grip handle properties. In addition, once the test racket frame was configured the racket, zero, first, and second moments of inertia were measured. The racket's inertia properties were adjusted accordingly using lead tape until all rackets were within the tolerances specified for each measure using the Weber fractions, shown in Table 1. No published Weber fractions existed for the first moment, so a value close to the second moment was selected as suitable. 
Table 1 Tolerances for test rackets to ensure imperceptible differences in inertia characteristics

\begin{tabular}{llll}
\hline $\begin{array}{l}\text { Moments of inertia } \\
\text { measure }\end{array}$ & $\begin{array}{l}\text { Weber } \\
\text { fraction }(\mathrm{k})\end{array}$ & Tolerance & Source \\
\hline Zero & 0.085 & $26 \mathrm{~g}$ & $\begin{array}{l}\text { Ross and } \\
\text { Brodie [14] }\end{array}$ \\
$\begin{array}{l}\text { First } \\
\text { Second }\end{array}$ & 0.025 & $0.8 \mathrm{~cm}^{2}$ & - \\
\hline
\end{tabular}

To investigate the effect of handle shape, four different shapes were used, shown in Table 2. The Duraform PA (similar properties to Nylon 12) handles were produced using rapid manufacturing technologies, in this case a Vanguard HS laser sintering machine (3D Systems Inc.). Each of these shapes investigated the effect of handle shape on player perceptions, but care was taken to ensure that the shapes were appropriate for players to use. Standard racket handle sizes range from size $0(100-103 \mathrm{~mm}$ circumference) to size 7 (122-125 mm circumference), but typically only handle sizes $2-6$ are available. Four different handle sizes were used on the test rackets ranging between sizes 2 and 5, as larger sizes were found to be too uncomfortable for players to use.

The grips available in the market were analysed and placed into four categories: polyurethane grips, leather grips, cotton towelling grips, and overwraps (thin grip wraps that are wound over the top of a standard grip). A range of different grips were selected for each of these categories with the overwraps combined with both polyurethane and leather grips underneath. Eight different grip surface combinations were therefore produced. The heavily textured polyurethane was used solely with the standard shape racket handles to ensure that test participants did not experience

Table 2 Handle shape profiles used

\begin{tabular}{|c|c|c|}
\hline \multirow[t]{6}{*}{ Shape profile } & Shape & Material \\
\hline & Standard & PU foam \\
\hline & Standard rotated & Duraform PA \\
\hline & Oval & Duraform PA \\
\hline & Six-sided & Duraform PA \\
\hline & & \\
\hline
\end{tabular}

sensory confusion. The rackets were altered in these ways to provide a stimulus to elicit responses from the test subjects about the grip/handle. A test protocol similar to Davies et al. [12] was used to gather 16 subjects' responses immediately after using their designated test racket for a play warm-up session. All participants were Lawn Tennis Association level 3 coaches or those players recommended by coaches as sufficiently competent; the subject ages ranged from 18 to 41, with a mean age of 25.3 years and an average of over 18 years playing experience per subject. Towards the end of the study, saturation of the data began to emerge, agreeing with the trend found by Davies et al. [12], suggesting that sufficient subjects had been interviewed. Experienced subjects were selected, as Roberts et al. [6] believed that elite player's sensitivity to differences in equipment characteristics increases as the player improves and gains experience. They have also been found to better identify inadequacies or preferences with products and are often more confident with their responses than less experienced users [16]. They also ensured that more consistent impacts were produced with each test racket and technique variation was minimized. This is important as ball impact position can influence the perceived racket properties. Loughborough University's Ethical approval board approved the test procedure and methods of data collection and storage.

The structured relationship model procedure requires the test participants to use the product as they would during their normal use, replicating as many of the tasks they perform as possible. This is to be balanced against time constraints and the number of products for the participants to test. For the racket study, the protocol required a test with each racket similar to a 5 min warm-up that subjects would conduct prior to a typical match. Subjects were tested in pairs to allow this procedure to be conducted more efficiently. New balls were provided for each pair of subjects to ensure consistency. The players would play forehand, backhand, and volley shots during the course of the warm-up and then finish with some serves. At the end of each 5 min test period, the subjects would be interviewed by their assigned interviewer about the perceptions they experienced from each racket. Rackets were assigned to each subject using a modified Latin square, which removed order effects and ensured each pairing used all eight rackets; therefore, each individual within a pair would use two different rackets from their partner. Each subject and interviewer was provided with a wireless lapel microphone, so that all conversations during the course of the test could be recorded for transcription at a later date and the interviewer could focus on the subject's responses. 


\subsection{Interview procedure}

Open-ended questions were used to elicit subject perceptions of the equipment; these were provided as a series of prompt questions on an interview guide, which helped to structure the interview. The advantage of open-ended questions is that they are flexible, allow the interviewer to probe where necessary to provide more depth to the response, or clear up any misunderstandings. They also help the subject and interviewer to establish a rapport because of their flexible nature. The interviewers were free to use these and any other questions they felt necessary with the test subject. Open-ended situations can also result in unexpected or unanticipated answers, which may suggest new relationships or hypotheses [17]. For effective use of this technique, the interviewer must try to minimize the descriptive vocabulary used until the subject introduces them; this ensures that the subject uses their own vocabulary. Once introduced, the interviewer would typically probe the explicit meaning of the descriptors, as appropriate, and would then be able to use these terms in future probing questions with the subject. The interviewer is free to probe the subjects responses where necessary, for example, if the subject stated 'the grip feels dry' the interviewer could be expected to probe 'what do you mean by dry?', this process allows the accumulation of subject vocabulary and explanations of definitions of the words used by players. In addition, the interviewers would note any descriptors used by the test population.

\subsection{Analysis of data}

The microphones recorded the players while they were playing, even though they were not interviewed during this time. This enabled the subjects to provide relevant comments on the spot, and all of these comments were then identified in the transcripts. Verbatim transcripts of all 16 interviews were made and these were analysed to provide quotes, the basic unit of analysis was a quote. A quote is defined by ' $a$ statement made by the subject, which is selfdefinable and self-delimiting in the expression of a single, recognizable aspect of the subject's experience' [18] and varied in length from a word to a paragraph. Inductive content analysis was used to organize the quotes into interpretable and meaningful themes and categories and using this approach; the themes and categories emerged from analysis of the quotes rather than being predetermined. This approach was effectively used in previous studies $[\mathbf{6 - 9}, \mathbf{1 2}]$. The quotes are clustered by comparing and contrasting each quote with all the other quotes and emergent themes to unite quotes with a similar meaning and separate quotes with different meanings [19]. The analysis process is inductive and requires many iterations comparing and contrasting quotes and categories to create themes that accurately reflect subjects' perceptions. The example in Fig. 1 shows how similar quotes are clustered together, from the raw data, all themes are clustered into higher level themes until they can be clustered no further and have become a general grouping for a wide range of quotes, also known as a general dimension, forming a tree-like structure. In total, four general dimensions of 'feel' from the grip/handle were identified in this study: handle surface, grip factors, in-game gripping, and impact perceptions. Generally, not all quotes can be clustered as raw data themes, this occurs when quotes differ in their levels of descriptiveness. This varies on the subject's ability to articulate their answers and the complexity of the perception. Greater description occurs with more articulate subjects and complex multi-faceted perceptions. Those themes that involve lower quantity of description do not always carry through all inductive levels and therefore they immediately become a higher inductive level. QSR NUDIST software was used to analyse the pages of transcription identifying 2280 quotes, which clustered into 54 themes; the actual number of quotes identified is lower as some quotes were clustered into more than one theme.

\subsection{Formation of the model}

Roberts et al. [6] and Davies et al. [12] further developed the tree structures to produce a structured relationship model. The structured relationship model was formed from the previously constructed tree structures by using the general dimensions as the hub for each dimension orientating the lowerorder themes around them accordingly. Interdimensional relationships were identified using QSR NUDIST software to analyse the clustering of the transcripts. Searches were conducted for quotes which were coded in more than one cluster or quotes which were immediately preceded or followed by another coded quote; this would suggest that there was a conscious relationship between the factors. With these quotes highlighted by the NUDIST package, they were then verified as valid relationships by re-reading the transcripts. Figure 2 shows the structured relationship model, with ten inter-dimensional relationships displayed as dashed lines.

\section{DISCUSSION OF MODEL RESULTS}

The model was able to identify key elements of a tennis racket grip/handle, which influenced player perception. This information is useful as it not only highlights the areas for possible customization, but 
"... because of the ridges I feel I can secure my hand quite strongly quite securely on the grip again "

" It doesn't really feel right I lost the control of it, like the whole rackets meant to fit with your hand isn't it but that felt rough, my serve was going all over the place"

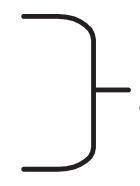

SECURITY OF GRIP ON HANDLE

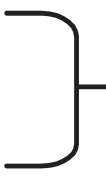

REQUIREMENTS OF HEEL PAD

FIT IN racket almost like it would come out of the hand"

"...got your meaty bit there [palm of hand] to get your hand behind already I feel wobbly with that I don't think I will be long with this one dreadful performance terribly uncomfortable"

"When I serve I have got half of that smooth bit and half of the ridges so my thumb is feeling a different texture to my three fingers and that seem to effect me for some reason"

"when you've got hard patches then soft patches some fingers are gripping tighter than other fingers and when you've got one finger gripping tighter than the others you haven't got a firm grip and the racket head moves..."

Fig. 1 Example of process of quote clustering by uniting similar themes

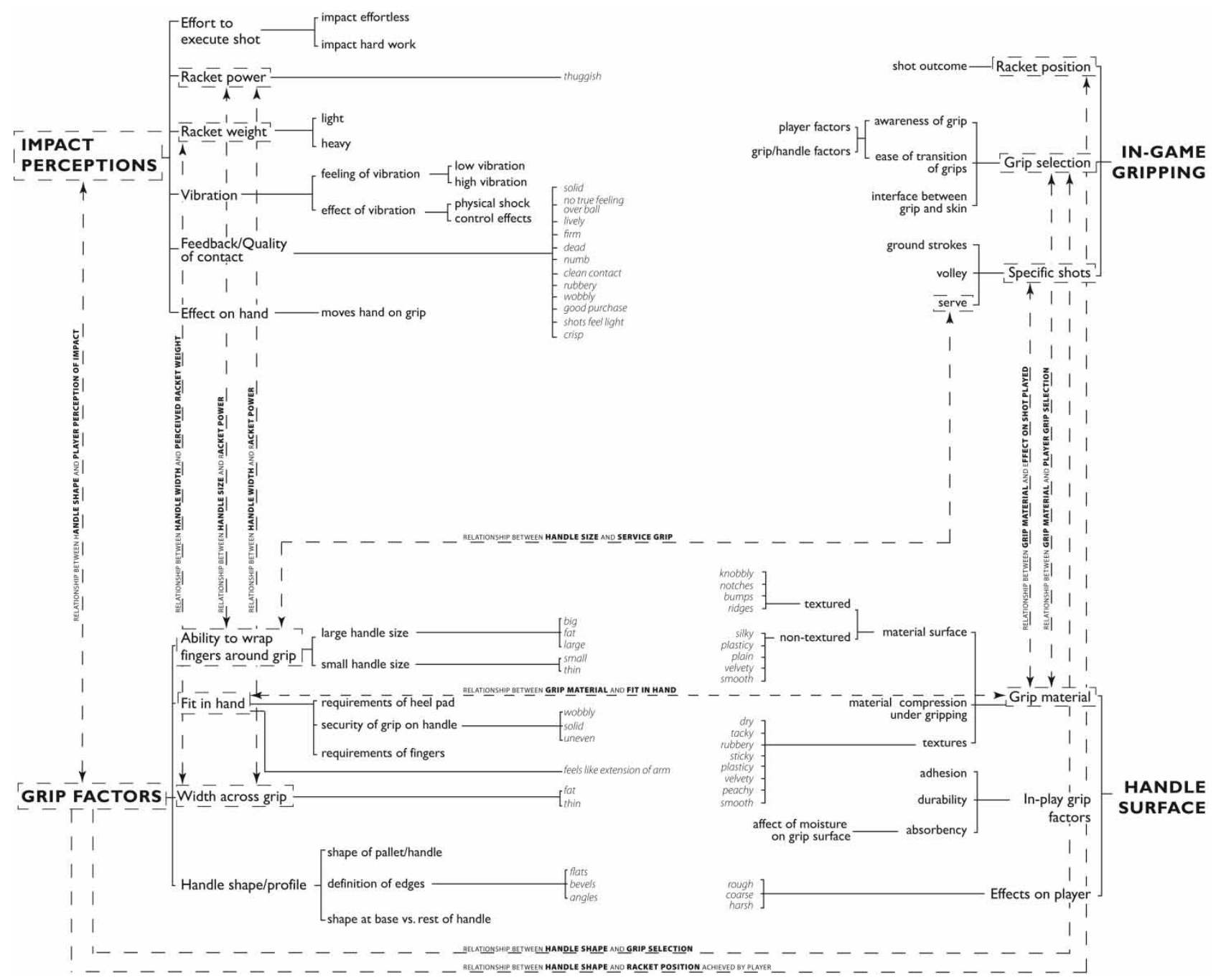

Fig. 2 The structured relationship model, with the inter-dimensional relationships highlighted using dashed lines 
the inter-dimensional relationships help to identify interaction between the different handle characteristics that may be affected when customizing the different features. Examples of this were the effect of grip material on the shot selection of players and their transition between grips. The width of the handle was also found to influence the perceived racket weight. A key trend was found that players selection of handle size appeared to be a compromise. Some players suggesting that they preferred larger racket handles for serving, but found these handles more restrictive for ground strokes as they believed it inhibited wrist movement. Larger handles were also commented to make the rackets feel more powerful, although control was compromised.

One problem identified with the methodology used was, as many rackets were to be used during a test of suitable length meant that players were only able to spend $5 \mathrm{~min}$ with each racket. Subjects mentioned that grip properties are likely to change over time and effects such as grip wear, durability, and sweat absorption or responses to sweat accumulation were not observed as effectively as possible. Subjects also mentioned that they thought infrequently about the grip and interaction with their hand during normal play.

\section{METHODS OF MODEL VALIDATION}

The structured relationship model only identifies the factors perceived as important by the test population used to develop the model. Careful selection of test population can help to ensure that the factors identified are likely to be representative of the general population. However, methods of model validation are available to help determine the relative importance and value of the factors identified by the model. Two suitable model validation methods are proposed: one for identifying the relative importance of each model factor and the other for identifying the value of each characteristic to the product.

To investigate the relative importance of each of the identified factors, scaled response questions can be used. This approach was adopted by Roberts et al. [6] with a postal questionnaire and by using an internet-based questionnaire for the featured racket handles study. Both these approaches attempted to gain responses from a wider population and to determine the relative importance of the factors identified by the respective models. For the racket study, a 1-9 scale was used to rate how important each of the factors identified was to the respondent's game (see example in Fig. 3). There were eight questions that were each posed with regard to the 'ideal' forehand, backhand, and serve, investigating the ideal sensation and importance of four handle characteristics. A further eight questions were posed about the influence of general handle properties on respondents performance.

An online questionnaire was developed and the hyperlink distributed to 717 relevant email addresses. Over a 2-month period, 117 complete responses were provided. The respondents also provided ratings to scale the level of each factor that they would expect to experience for their ideal shot so that approximate level of sensations could be determined.

For the tennis racket handle, the feel of the grip surface was identified as the most important factor (with a mean importance rating of 7.4 out of $9, \sigma=1.8$ ). The least important factors were the feel of impact vibration for the serve stroke (mean importance ratings 5.4 out of $9, \sigma=2.4$ ). However, there was considerable deviation in subject responses for the importance of vibration.

The use of customization to add value to a product is one of the main drivers behind the inclusion of customization into products. Therefore, for some products, it may be more appropriate to investigate the value of each of the identified product factors, as there is little worth in customizing a feature that does not add to product value. Campbell [1] proposed that a functional analysis of the product design should be undertaken as to determine the relative contribution of each feature on its overall value. He outlined a method to conduct this. In his approach, the target customer is provided with a product with alternative versions of an individual feature and then asking the customer how much they would be willing to pay for each feature. The value contribution of the features can then be approximated. The resulting outcome of the functional analysis is a list of possible product features with their relative values. These values should add

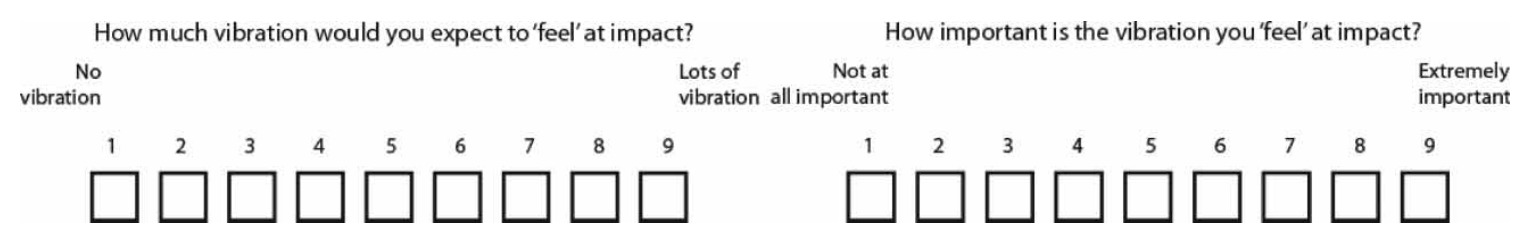

Fig. 3 Example of scaled response questions used to help validate the structured relationship model. 
up to the price that the product can be sold for. The designer would approximate how much it would cost to customize each feature, incorporating the extra design required and increased manufacturing cost. A value index is then calculated as

$$
\text { value index }=\frac{\text { extra price paid by customer }}{\text { cost of customization }}
$$

Features that yield the highest value indices are most appropriate for customization, as these will provide the greatest return on investment. This method of validation was not performed as part of the current case-study, as it was identified as a more suitable exercise for a manufacturer to target or define their core customer for analysis.

\section{CONCLUSIONS}

The structured relationship modelling technique is a useful alternative to the conventional approaches of consumer interviews and focus groups, with one of the major advantages being that the customer can actually use the product to generate their responses rather than being asked to recount their experiences of the product. This situation ensures that the data provided by the subject are gained in a controlled environment and that their responses are not predominantly based on previous experiences.

In the current article, the application of the modelling process is discussed in relation to sports equipment and tennis racket handles in particular. However, it is possible to use this procedure in a number of different areas. Although this procedure was discussed with the use of determining customizable product features, it may also be used to determine features of a product that need to be redesigned or improved on a particular product.

The methodology is considered suitable for use in a commercial situation, where, for example, a company may choose to develop a structured relationship model of a specific product and refresh it periodically, for example, every 5 years. A company may also choose to redevelop the model as either the target customer changes or major changes to the product's market become apparent. The model would be used as a reference for all relevant products with the documented information used to help develop initial product requirements, which may, in turn, be refined by further in-depth market research or investigation. The economic implications of this technique for a company are found in the time and resources required to develop the model. Griffin and Hauser [20] found that over 90 per cent of the customer needs were identified after 25-50 interviews. However, Roberts et al. [6] and Davies et al. [12] and this study found saturation of subject responses after analysing approximately 15 subjects, possibly because of more effective elicitation of data. Therefore, one would recommend that 15-20 subjects are required to effectively gather sufficient data for analysis with this technique. The duration of testing for each subject should last no longer than $1 \mathrm{~h}$ to prevent user fatigue and loss of motivation. The resources required for preparation of the test samples cannot be predicted as this will be dependent on the type of product and the factors to be investigated. The time taken to complete the subject testing is again dependent on subject and test facility availability. The overall analysis and production of the structured relationship has been found from experience to take an individual approximately 1-2 months, dependent on the amount of time the individual is able to dedicate to the analysis.

In general, recommendations for using this technique are to ensure that when conducting tests with multiple product alternatives that these tests are of duration no longer than $1 \mathrm{~h}$ per test subject to reduce the effects of boredom and sensory fatigue. All interviewer-subject conversations should be recorded and transcribed, and the interviewer should also be given the ability to note any non-verbal information provided by each of the subjects to ensure effective analysis. The use of test articles with a range of properties is necessary to stimulate a range of responses from the subjects. However, these properties must be within the ranges of those featured typically on the product to ensure that it remains useable and a single unconventional product feature does not distract the subjects.

In general, the technique is easily performed with broader product areas, for example, the perception of a whole shoe as opposed to just the upper of the shoe. The difficulty arises from users being unable to easily separate elements of the product that may not be the focus of the investigation from the element that is. This occurs as elements, such as the upper of a shoe is always attached to the sole of the shoe, so the users' experience is always a result of some mutual interaction between these two elements. In these focused situations, the analysis has to be more thorough to ensure that the contributions of these additional elements are recognized. However, this technique has been demonstrated to effectively break down a previously unpublished model of the tennis racket into models solely for the ball [12] and for the racket handle in this study. Consideration must also be given to the features examined by this method, particularly with regard to customization. Not all features of a product may be suitable for investigation or subsequent customization. Those features that are critical to the safe operation of a product or those that form part of a product's intellectual property are two examples of areas that may not be suitable. 


\section{ACKNOWLEDGEMENTS}

The authors would like to thank the Wolfson School of Mechanical and Manufacturing Engineering, Loughborough University for providing the facilities and technical staff who enabled this project to be conducted. The authors also thank the EPSRC for providing the funding that allowed this research project to be undertaken and Dunlop Slazenger International Ltd for their support of the project and the provision of rackets and balls to make the test possible. Appreciation is also extended to the tennis players whose time and effort made this study possible.

\section{REFERENCES}

1 Campbell, R. Customer input and customisation, Rapid manufacturing: an industrial revolution for the digital age, ch. 3, 2006, pp. 19-37 (John Wiley and Sons, Ltd, London).

2 Duray, R. Mass customization origins: mass or custom manufacturing? Int. J. Oper. Prod. Manage., 2002, 22(3), 314-328.

3 Ulrich, K. and Eppinger, S. Product design and development, 1995 (McGraw-Hill, USA).

4 Jiao, J. and Tseng, M. M. Customizability analysis in design for mass customization. Comput.-Aided Des., 2004, 36, 745-757.

5 Barrass, D. F. The feasibility of sports grips customisation using rapid manufacturing methodologies. $\mathrm{PhD}$ Thesis, Loughborough University, 2006.

6 Roberts, J., Jones, R., Harwood, C., Mitchell, S., and Rothberg, S. Human perceptions of sports equipment under playing conditions. J. Sports Sci., 2001, 19, 485-497.

7 Gould, D., Eklund, R., and Jackson, S. 1988 U.S. Olympic Wrestling Excellence: I. Mental preparation, precompetitive cognition, and affect. Sport Psychol., 1992, 6, 358-382.

8 Gould, D., Eklund, R., and Jackson, S. 1988 U.S. Olympic Wrestling Excellence: II. Thoughts and affect occurring during competition. Sport Psychol., 1992, 6, 383-402.

9 Hanton, S. and Jones, G. The acquisition and development of cognitive skills and strategies in making the butterflies fly in formation. Sport Psychol., 1999, 13(1), $1-21$.

10 Scanlan, T., Ravizza, K., and Stein, G. An in-depth study of former elite figure skaters: introduction to the project. J. Sport Exerc. Psychol., 1989, 11(1), 54-64.

11 Scanlan, T., Ravizza, K., and Stein, G. An in-depth study of former elite figure skaters: sources of enjoyment. J. Sport Exerc. Psychol., 1989, 11(1), 65-82.

12 Davies, G., Rothberg, S., Jones, R., and Roberts, J. Player perception evaluation of 'feel' in tennis ball impacts. Tennis science and technology, 2003, pp. 71-78 ITF, London.

13 Young, C., Fleming, P., Dixon, N., Jones, R., and Roberts, J. Correlating player performance tests with human perceptions for synthetic field hockey pitches. The Engineering of Sport 5: In Proceedings of the 5th International Conference on the Engineering of Sport Davis, (Eds M. Hubbard, R. Mehta, and J. Pallis), California, USA, September 2005, pp. 517-523 (ISEA).

14 Ross, H. and Brodie, E. Weber fractions for weight and mass as a function of stimulus intensity. Quart. J. Exp. Psychol., 1987, 39A, 77-88.

15 Brody, H. Player sensitivity to the moments of inertia of a tennis racket. Sports Eng., 2000, 3, 145-148.

16 von Hippel, E. The sources of innovation, 1988 (Oxford University Press, New York, NY).

17 Cohen, L. and Manion, L. The interview. Research methods in education, 3rd edition, 1980, pp. 307-335 (Routledge, London, New York).

18 Cloonan, T. Experiential and behavioural aspects of decision-making. Duquesne studies in phenomenological psychology (Eds A. Giorgi, W. Fischer, and R. Von Eckartsberg), 1971, vol. 1, pp. 112-131, (Duquesne University Press, Pittsburgh).

19 Patton, M. Qualitative evaluation and research methods, 2nd edition, 1990 (SAGE Publications, California).

20 Griffin, A. and Hauser, J. Qualitative: the voice of the customer. Mark. Sci., 1993, 12(1), 1-27. 